POLIGRAFÍAS. REVISTA DE TEORÍA LITERARIA Y LITERATURA COMPARADA. NÚMERO 1. NUEVA ÉPOCA.

() UNAM TODOS LOS DERECHOS RESERVADOS

https://doi.org/10.22201/ffyl.poligrafiasnuevaepoca.2011.1.1649

\title{
Peter Handke y Wim Wenders: dos lenguajes, una estética
}

Violeta VÁzQuez CASTRO

Universidad Nacional Autónoma de México

Cuando Peter Handke (Griffen, 1942) y Wim Wenders (Düsseldorf, 1945) se conocieron en 1966, ya ambos habían ideado los principios estéticos en los que se sustenta su producción: su postura frente al quehacer artístico es a tal grado cercana que, al menos durante la década de los 70, su obra se desarrolla cuasi en paralelo. Congenian de inmediato, y a partir de ese momento no sólo viven una larga amistad sino también llevan a cabo trabajos en conjunto en los que literatura y cine confluyen amigablemente dando como resultado propuestas únicas.

Toca vivir a estos autores la difícil época de la posguerra en la que la reflexión sobre el papel del artista, sobre lo poético frente a lo político, no sólo en la Alemania occidental sino también en los otros países de habla alemana, es obligada. El acto creativo difícilmente puede separarse de una política que llevó al mundo a una guerra de enormes proporciones, sobre todo porque esa realidad social obstaculiza toda búsqueda individual de identidad: “Den deutschen Kindern nach dem Krieg war freilich dieser Aufbruch versagt -und damit strenggenommen, auch jede Hoffnung. Sie sind [...] infiziert von der Barbarei ihrer Väter. Die Geschichte lastet auf ihnen und befleckt im nachhinein die Erinnerung an die Kindheit. So sind sie ihrem Ursprung doppelt entfremdet" (Buchka, 1985: 36). ${ }^{1}$

Los temas que interesan al joven Peter son el cine, la política y, sobre todo, la literatura. Ya en sus primeros ensayos, escritos entre 1965 -cuando cuenta con veintitrés años- y 1971, pero sólo publicados hasta 1972 con el título Ich bin ein Bewohner des Elfenbeinturms (1972b) (Soy un habitante de la torre de marfil), discurre sobre ellos. En el ensayo que da título al libro, escrito en

\footnotetext{
${ }^{1}$ Las traducciones del alemán al español son mías. “A los niños alemanes de la generación después de la guerra este resurgimiento les fue negado, y con ello, por supuesto, hablando estrictamente, también cualquier esperanza. Fueron
} 
1967, define a la literatura como algo más que un medio de expresión: “Literatur ist für mich lange Zeit das Mittel gewesen, über mich selber, wenn nicht klar, so doch klarer zu werden. Sie hat mir geholfen zu erkennen, da $\beta$ ich da war, da $\beta$ ich auf der Welt war [...] So bin ich eigentlich nie von den offiziellen Erziehern erzogen worden, sondern habe mich immer von der Literatur verändern lassen" (1972b: 19). ${ }^{2}$

Para Handke, detrás de la literatura se halla todo lo demás: educación, crecimiento, vida, realidad; todo viene de la literatura y de ella parte todo. $Y$ es que la realidad de la literatura lo volvió atento y crítico frente a la realidad verdadera, de suerte que vida y literatura son indisolubles. La literatura es el medio para entenderse a sí mismo y, por lo tanto, sólo puede convertirse en una búsqueda constante. Sus incursiones en todos los géneros, desde la poesía, el teatro y la narrativa hasta guiones para televisión, radio y cine, son prueba fehaciente de ello. Como lector y como escritor reconoce en la literatura siempre nuevas posibilidades y, dado que cada nueva posibilidad envejece en el momento de ser puesta a prueba, le es necesario volver a experimentar. Así pues, la experimentación incesante define su método de escritura. Parte de la tesis que "Eine Möglichkeit besteht für mich jeweils nur einmal. Die Nachahmung dieser Möglichkeit ist dann schon unmöglich. Ein Modell der Darstellung, ein zweites Mal angewendet, ergibt keine Neuigkeit mehr, höchstens eine Variation" (1972b: 20). ${ }^{3}$

Desde sus primeros trabajos, publicados en 1966, la novela Los avispones (Die Hornissen) e Insulto al público y otras piezas (Publikumsbeschimpfung und andere Sprechstücke) experimenta a tal punto que "Was er schrieb und wie er urteilte, das wirkte jedesmal neu und provokant" (Lorenz, 1989: 10). ${ }^{4}$ Su escritura manifiesta desde sus inicios, como afirma Hugo Dittberner, algo que lo fuerza a apropiarse de una nueva manera de escribir (1989: 3).

En Los avispones, Handke ignora los convencionalismos de la novela y pone el método de escritura a la vista del lector. La novela habla de las dificultades del narrar. Más aún, “Thema

[...] infectados por la barbarie de sus padres. La historia pesa en ellos y mancha la memoria de la niñez. Así fueron doblemente enajenados de sus raíces".

2 "La literatura ha sido para mí durante mucho tiempo el medio de encontrar, si no claridad, por lo menos más claridad sobre mí mismo. Ella me ayudó a ver que ahí estaba yo, que yo estaba en el mundo [...] realmente yo nunca fui educado por los educadores oficiales, sino que me dejé transformar por la literatura"

3 “cada posibilidad existe nada más una vez. La imitación de esta posibilidad ya es imposible. Un modelo de representación utilizado una segunda vez no da por resultado ninguna novedad, cuando mucho una variación".

4 "lo que escribió y cómo lo juzgó, causaba la impresión de nuevo y provocador". 
der 'Hornissen' ist, von der Schreib-Methode her betrachtet, die Demonstration von (literarischer) Vermitteltheit allen (literarischen) Erzählens, vom Zweck dieser Schreib-Methode (nämlich die Welt zu erobern) her betrachtet, die Aufhebung der Kindheit in der Erinnerung" (Mixner, 1977: 19-20). ${ }^{5}$

En Insulto al público, considerado como una rebelión literaria contra lo literario (Pütz, 1982: 4), el acento recae forzosamente en la palabra. Oradores toman el lugar de los actores y, sentados frente al público, se dirigen a él y le advierten francamente: "Sie werden kein Spiel sehen. Hier wird nicht gespielt werden" (Handke, 1966b: 15). ${ }^{6}$ La pieza cumple al pie de la letra lo que el título anuncia:

Ihr seid profilierte Darsteller, ihr Maulaffenfeilhalter, ihr vaterlandslosen Gesellen, ihr Revoluzzer, ihr Rückständler, ihr Beschmutzer des eigenen Nests, ihr inneren Emigranten, ihr Defätisten, ihr Revisionisten, ihr Revanchisten, ihr Militaristen, ihr Pazifisten, ihr Faschisten, ihr Intellektualisten, ihr Nihilisten, ihr Individualisten, ihr Kollektivisten, ihr politisch Unmündigen, ihr Quertreiber, ihr Effekthascher, ihr Antidemokraten, ihr Selbsbezichtiger, ihr Applausbettler, ihr vorsintflutlichen Ungeheuer, ihr Claqueure, ihr Cliquenbildner, ihr Pöbel, ihr Schweinefra $\beta$, ihr Knicker, ihr Hungerleider, ihr Griesgräme, ihr Schleimscheißer, ihr geistiges Proletariat, ihr Protze, ihr Niemande, ihr Dingsda (1966b: 46-47). ${ }^{7}$

Nada en esta suerte de antiteatro, de teatro contra el teatro, en el que los roles y las palabras se trastocan, pretende tener una intención mimética, pues la paradoja se hace evidente y la obra resulta más real que la realidad misma. En términos handkeanos: más literatura que realidad. Como lo expresa el propio Handke: “Es interessiert mich als Autor übrigens gar nicht,

\footnotetext{
5 “el tema de Los avispones, visto desde el método de escritura, es la demostración de las relaciones (literarias) en todo tipo de narración (literaria); es desde el punto de vista del objetivo de este método (conquistar el mundo), la desaparición de la niñez en la memoria".

6 "Ustedes no verán representación alguna. Nada aquí será actuado".

7 "Ustedes son actores perfilados, ustedes los boquiabiertos, ustedes los compañeros sin patria, revoltosos, atrasados, lavando en público los platos sucios, emigrados internos, pesimistas, revisionistas, revanchistas, militaristas, pacifistas, fascistas, intelectualistas, ritualistas, individualistas, colectivistas, incompetentes en la política, peleoneros, buscadores de efectos, antidemócratas, acusadores de ustedes mismos, mendigos del aplauso, monstruos prediluvianos, alabadores, creadores de clanes, plebes, comida de cerdos, codos, hambrientos, gruñones, aduladores, proletarios de la inteligencia, fanfarrones, ustedes los nadie, los fulanos".
} 
die Wirklichkeit zu zeigen oder zu bewältigen, sondern es geht mir darum, meine Wirklichkeit zu zeigen (wenn auch nicht zu bewältigen)" (1972b: 25). ${ }^{8}$

1966 también es el año en el que Wenders filma su primer cortometraje, Schauplätze (Escenarios). ${ }^{9}$ Como a muchos otros cineastas de su generación, le toca empezar de cero, partir de un cine "Ohne Tradition, ohne Vaterfiguren, die zum Vorbild taugten und ohne eine Filmsprache, die nicht vom vergangenen Unheil angesteckt war" (Buchka, 1985: 13).10 El nacionalsocialismo en Alemania dio a la cinematografía el peor golpe de su historia, centrando su producción en películas propagandísticas y, en la posguerra, un cine sólo de entretenimiento, distractor y divertimento de un ciudadano medio que lleva ya décadas tratando de olvidar la Historia. Así, entre 1933 y 1965, la calidad del cine alemán es inexistente; pero ya para la década de los 60, cuando se hace posible, con los medios masivos de comunicación, difundir a nivel internacional noticias e ideas casi en el momento en el que nacen, los jóvenes cineastas alemanes se dan a la tarea de producir obras de calidad. La creación de Die Hochschule für Fernsehen und Film, en 1967, representó la oportunidad que necesitaban. La escuela de cine se convertirá por cuatro años en el lugar de estudio del joven Wim, quien al principio tenía el deseo de devenir crítico de cine, sin saber que la dirección le vendría de la práctica. Y es a través del rock que ingresa al mundo del cine, primero como espectador, después como crítico para las revistas Filmkritik, Süddeutsche Zeitung y Twen (Wenders, 1988b) y, finalmente, como director.

El rock y el cine le producen imágenes y sentimientos similares. De hecho el rock es el tema del cortometraje 3 Amerikanische $L P^{\prime} s{ }^{11}$ en el que, por cierto, Handke participa como guionista y actor. Comienza con un close up de unas manos y algunos discos LP, de los que se puede ver claramente Astral Week de Van Morrison, Green River de CCR y Christo Redentor de Harvey Mandel y, durante doce minutos, se oyen fragmentos de estos LP's, mientras la cámara muestra, desde un automóvil, zonas industriales en los alrededores de Munich -edificios en

\footnotetext{
8 "como autor, no me interesa en absoluto mostrar la realidad o someterla, sino que mi intención es mostrar mi realidad (lo que no significa someterla)".

${ }^{9}$ Este primer cortometraje se perdió ya que no existía copia alguna. Duración: $10 \mathrm{~min}$.

10 "sin tradición, sin figuras paternas que pudieran servir de modelo, y sin un lenguaje cinematográfico que no estuviera infectado por los males pasados".

11 1969. Dirección, cámara, edición: Wim Wenders. Producción: HR, Frankfurt. Guión: Peter Handke. Música: “Slim Slow Slider", Van Morrison; "Green Water", Creedence Clearwater Revival; "Made in the Water", Harvey Mandel. 16 mm., Eastman Color. Voces: Wim Wenders, Peter Handke. 13 min.
} 
construcción, gasolinerías, un autocinema- desmitificando la idea de una Alemania perfecta; entretanto se escuchan en voz off a Wenders y a Handke hablando sobre lo que miran desde el auto y sobre el rock.

En una de sus críticas publicadas en junio de 1969, Wenders resalta la íntima relación entre el rock y el cine; explica cómo en el filme An einem Freitag in Las Vegas ${ }^{12}$ se ven las calles de la ciudad muy temprano por la mañana; pues esas mismas imágenes producen al futuro cineasta los LP's Christo Redentor y Righteous de Harvey Mandel, y aconseja: “Wenn man den Film nicht sehen kann, kann man sich die beiden LP's von Harvey Mandel anhören" (1988b: 17). ${ }^{13}$

Su estética también está marcada por la experiencia como espectador de cine: en el año que estuvo en París intentando matricularse en la Escuela de Cine -en la que, sin embargo, no fue aceptado- visita asiduamente la cineteca y ve en promedio cinco películas diarias. Ritmo que cambia necesariamente su manera de ver cine, obligándolo a retener únicamente imágenes sueltas y dejar la historia un tanto de lado; no obstante, las películas siguen siendo efectivas, pues le producen una impresión que como espectador guarda en su memoria: es capaz de recibir el mensaje sin necesidad de retener la historia. Más tarde, Wenders materializará esta experiencia en sus propias películas.

Además, frente a la vida -y por ende, frente a la muerte- cualquier historia tendría que perder sentido. Ya desde Same player shoots again ${ }^{14}$ la historia sucede en una corriente subterránea fuera de la pantalla. Lo que muestra el cortometraje es un plano de tres minutos en el que se ven solamente las piernas de un hombre que corre trastabillando, como si estuviera herido, y este mismo plano se repite cinco veces con una coloración diferente cada vez. Pero es precisamente en este "acaso va herido" que reside una historia que el cineasta no cuenta.

Con esta forma de hacer cine, Wenders pone en el tapete de la discusión una polémica tan vieja como el propio cine y que, sin embargo, ha seguido vigente: por un lado, considerar el cine como simple reproducción de lo real (los hermanos Lumière) y, por otro, considerarlo como un medio para narrar (Meliès, Griffith y Eisenstein). Este dilema también incide en la

\footnotetext{
${ }^{12}$ Del director español Antonio Isasi-Isasmendi. 1967. Con Elke Sommer.

13 "en caso de que no se pueda ver la película, se pueden oír los LP's de Harvey Mandel".
} 
concepción estética del cineasta -un cine que reflexiona constantemente sobre el medio en el que se expresa- y lo pone en el centro de su constante experimentación.

Handke comparte su postura frente al contar historias: si la vida es una historia, es absurdo que el arte se encargue de contarla. En Weissagung (1966b) (Presagio), experimenta con un gran paradigma en donde las frases no guardan una relación de fondo sino de forma. Axiomas que no interesan a no ser que se les otorgue un lugar para que muestren lo evidente: “Die Ratte wird schlafen wie eine Ratte [...] Die Toten werden totenblaß sein" (1966b: 56, 64). ${ }^{15}$ Más adelante, en Selbstbezichtigung (Autoinculpación), el paradigma conserva un sólo sujeto -Yoquien, al admitir todas las posibilidades de complemento, reconoce todas las posibilidades del ser. Escrita totalmente en pasado, reflexiona sobre lo hecho y lo no hecho, lo aprendido y lo no aprendido: “Ich habe die Obszönität mit der Originalität verwechselt. Ich habe das Leben mit dem Klischee verwechselt" (89). ${ }^{16}$ Tal simpleza obliga a las frases a recuperar su sentido.

Handke experimenta en estas piezas la negación del modelo del teatro y pone a prueba la función del arte. Afirma:

Die Sprechstücke bedienen sich der natürlichen Äußerungform der Beschimpfung, der Selbstbezichtigung, der Beichte, der Aussage, der Frage, der Rechtfertigung, der Ausrede, der Weissagung, der Hilferufe. Sie bedürfen also eines Gegenübers, zumindest einer Person, die zuhört, sonst wären sie keine natürlichen Äußerungen, sondern vom Autor erzwungen. Insofern sind die Sprechstücke Theaterstücke. Sie ahmen die Gestik all der aufgezählten natürlichen Äußerungen ironisch im Theater nach (Apud. Durzak, 1982: 83). ${ }^{17}$

La literatura de Peter Handke se ocupa, en primera instancia, de la materia prima con la que está hecha: palabras, que no son objetos, pues si solamente se usa la lengua para describir, entonces permanece muerta. El lenguaje no es una ventana a través de la cual se puedan ver los objetos, es una realidad por sí misma y su “Realität nicht geprüft werden kann an den Dingen,

\footnotetext{
${ }^{14}$ 1967. Dirección, producción, guión, fotografía, edición: Wim Wenders. 16 mm. 12 min.

15 "la rata dormirá como rata [...] los muertos estarán pálidos de muerte".

16 "Yo confundí la obscenidad con la originalidad. Confundí la vida con el clisé".

${ }^{17}$ Las piezas habladas se sirven de la forma expresiva natural del insulto, de la autoinculpación, de la confesión, de la declaración, de la pregunta, de la justificación, de la excusa, de la predicción, del grito de auxilio. Por lo tanto necesitan una contraparte, por lo menos de una persona que escuche, de lo contrario no serían expresiones naturales, sino forzadas por el autor. En tal medida las piezas habladas son piezas de teatro. Imitan, en el teatro, los gestos de todas las expresiones naturales de manera irónica.
} 
die sie beschreibt, sondern an den Dingen, die sie bewirkt" (1972b: 34). ${ }^{18}$ No es que niegue la descripción: es necesaria; pero no como la que se proclama como “Nuevo Realismo" en donde la palabra no funciona como tal sino que pretende tomar el lugar de una cámara fotográfica. Así, por ejemplo, “Die Beschreibung eines Computers, wenn sie schon geschieht, wird in der Syntax der Kompliziertheit eines Computers angepaßt sein müssen und nicht einfach im Stil eines Populärwissenschaftlers die Bestandteile aufzählen können" (1972b: 33-34). ${ }^{19}$ Así, en una suerte de juego de espejos, anula las fronteras entre realidad y ficción. Pero también las fronteras entre forma y fondo: el contenido es la forma y viceversa y en este juego reside el sentido de lo contado.

Juego de espejos que también se activa en el contacto con su amigo Wenders, quien, paralelamente y frente al criterio que impera en esos años para el cine experimental de ya no poder ver o casi no poder ver pues la rapidez o la distorsión con la que se presentan las imágenes lo impide, lleva su experimentación a girar alrededor precisamente de filmes que se mueven en ese plano que es, finalmente, la razón por la que uno va al cine. Por eso, las tomas que no permiten ver lo frustran al punto que el asunto es cuánto y no qué se puede ver (1988b). Wenders cree firmemente en la concepción visual de las cosas porque la verdad descansa en ellas. El cine se convierte, pues, en la única posibilidad de mostrar las cosas como son y sólo él puede “Die Existenz der Dinge retten" (1988b: 9). ${ }^{20}$

El interés esencial del cineasta se centra en las imágenes y sus obras lo confirman. En Silver City ${ }^{21}$ filma planos que toman las calles, sin cortes y sin movimientos de cámara, que duran tanto como el material lo permite -a la manera de los hermanos Lumière. En uno de estos planos sucede algo: la cámara estática toma el paisaje: una estación de tren, la vía, nadie en el horizonte. Wenders sabía cuándo llegaría el tren; sin embargo, un instante antes de que esto sucediera, alguien entra corriendo en la imagen desde la derecha y desaparece a la izquierda. Una fracción de segundo después entra el tren por la derecha. Dado que la película se filmó sin sonido, la llegada del tren resulta completamente inesperada. La intervención de este personaje

\footnotetext{
18 "realidad no se puede comprobar con las cosas que describe sino en las cosas que provoca".

19 "si se hace la descripción de una computadora debe de estar adaptada a la complejidad de la computadora y no sólo tener la capacidad de enumerar las partes al estilo de un científico popular".

20 "salvar la existencia de las cosas".
} 
lo hace reconocer tiempo después: "Ich glaube genau in diesem Augenblick begann ich, ein Erzähler zu werden" (1988a: 69).22

A Handke tampoco le preocupa la historia sino cómo es posible contarla; lo que él busca es retomar el modelo y mostrarle al lector nuevas posibilidades: “Neue Möglichkeiten zu lesen, zu spielen, zu überlegen: zu leben" (1985: 36). ${ }^{23}$ Para el escritor queda perfectamente claro que la literatura está hecha con palabras y no con cosas que son descritas con palabras, por lo que aspira a una literatura que sea leída palabra por palabra y no como en esas frases que el lector brinca al reconocerlas a primera vista.

Los personajes handkeanos no se relacionan con la realidad o con la ficción sino con las palabras. Por eso, en sus piezas teatrales, se concentra en ellas prescindiendo de la historia. A la vez, muestra que el modelo del teatro ya no aporta nada nuevo y la única manera de renovarlo es destruyéndolo, cuestionándolo como tal. Él mismo explica su concepción del teatro en uno de sus ensayos y reconoce que Bertolt Brecht le ayudó en su educación, ya que el modelo brechtiano de pensar se basa en la contradicción pues, por un lado, ese modelo artificial puede contradecir las posibilidades de cómo funciona la realidad y evidenciar lo artificial de la realidad misma y, por otro, mostrar que es posible cambiarla; sin embargo, reprocha a su maestro que agotó su modelo: la forma de sus obras pronto se ofreció como receta de un nuevo orden y, cuando mucho, como un juego de contradicciones (1972b: 51-53).

En 1968 Handke publica la pieza teatral Kaspar. En ella aparentemente recobra acción, escenario e historia. La obra empieza con una aclaración: “Das Stück 'Kaspar' zeigt nicht, wie ES WIRKLICH IST ODER WIRKLICH WAR mit Kaspar Hauser. Es zeigt, wie jemand durch Sprache zum Sprechen gebracht werden kann" (1968: 7). ${ }^{24}$ En ella cuestiona el discurso del poder, pues cualquiera conforma su vida, su personalidad, sus deseos, sus pensamientos en función del discurso dogmático, monotemático, repetitivo, hueco y al servicio de las clases dominantes. “Das Stück könnte auch 'Sprechfolterung' heißen” (1968: 8). 25

\footnotetext{
${ }^{21}$ 1968. Dirección, producción, guión, fotografía, edición: Wim Wenders. 16 mm. 25 min.

22 "Me parece que exactamente en ese instante me convertí en un narrador".

23 "nuevas posibilidades para leer, para jugar, para pensar: para vivir".

24 "La pieza 'Kaspar' no muestra cómo es o fue realmente con Kaspar Hauser. Muestra cómo se puede llevar a alguien a que, por medio del habla, hable".

25 “La pieza también podría llamarse 'Tortura del habla"”.
} 
Kaspar entra al escenario, difícilmente atina a caminar, lo intenta de mil maneras pero termina por caerse; permanece sentado e inmóvil y, acto seguido, empieza a hablar repitiendo siempre la misma frase: "Ich möchte ein solcher werden wie einmal ein andrer gewesen ist" (1968: 13). ${ }^{26}$ Se nota a todas luces que no tiene idea de lo que dice. Poco a poco, a través de las palabras, se irá socializando; a través de los clisés que repiten los apuntadores: “cada quien es responsable de su progreso" o "distribuir correctamente el tiempo", Kaspar se pierde en su propio discurso para repetir el otro desgastado que le enseñaron: “Cada quien debe barrer delante de su propia puerta [...] cada quien se debe sonar". En Kaspar, Handke crea una figura exclusivamente escénica -Kaspar nace en escena, aprende en escena- y crea, a su vez, una parábola del teatro (Kesting, 1981: 124-125), además de poner en evidencia el abismo que se ha formado entre las palabras y los actos; muestra cómo pensamiento y lenguaje ya no pertenecen a la misma realidad; habla, en resumen, del poder de las palabras. “Das Theater ist bei Handke eben nicht Transpormittel fremder Bedeutungen, sondern ist selbst Wirklichkeit" (Kesting, 1981: 124$) \cdot{ }^{27}$

En cada nuevo trabajo, Handke tiene presente que con el tiempo un método pierde su efecto pues cuando se vuelve natural deja de oponer resistencia y se transforma en un patrón. Un método internalizado deja de ser pensado y como ya no obliga a la reflexión se vuelve acrítico. El método debe ocupar el primer lugar en la creación literaria, quedando la historia en un plano secundario -en todo caso, las historias son para ser contadas en el café, frente a la chimenea; además, si la literatura sólo buscara contar, los conocidos métodos que descansan en pensamientos y sentimientos conocidos serían más que suficientes (1972b). Por eso, cuando se trata de la creación literaria, Handke desarrolla lo que Michael Braun llama un "pathos" de la periferia (1989) o, como lo califica Olaf Hansen, un "pathos" de la forma, en donde la cercanía y la distancia de la figura del narrador cambia el material de la narración (1985).

Wenders desarrolla un pathos similar con respecto a las imágenes:

Im Verhältnis von Geschichte und Bild ähnelt für mich die Geschichte einem Vampir, der versucht, dem Bild das Blut auszusaugen. Bilder sind sehr empfindlich, ein bißchen wie

\footnotetext{
26 "Quiero ser alguien como alguna vez otro fue".

27 "El teatro de Handke no es medio de transporte para un significado ajeno, sino que es por sí mismo realidad".
} 
Schnecken, die sich zurückziehen, wenn man ihre Fühler berührt. Sie wollen nicht wie ein Pferd arbeiten: sie wollen nichts tragen und transportieren: weder Botschaft noch Bedeutung, weder Ziel noch Moral. Genau das wollen aber Geschichten (Wenders, 1988a: 71).28

Siguiendo este principio, ya en su primer largometraje Summer in the City ${ }^{29}$ filma escrupulosamente los hechos tal y como ocurren en tiempo real. De ahí que el road movie y sus técnicas le sean tan propias. En sus filmes abundan escenas que exponen llanamente el transcurrir del tiempo como la de este filme en donde la cámara permanece filmando durante el tiempo real en el que un auto pasa por un túnel y durante casi un minuto sólo se ve negro en la pantalla (1988a: 12).

Como hijo de su tiempo, Wenders acumula detalles que no están en relación de causa y efecto creando con ello una corriente subterránea que le da significación a los datos que presenta: es como un mosaico de imágenes que de ninguna manera intentan falsificar la realidad sino, sobre todo, hacerla transparente. Las historias de sus filmes corren en otra corriente de la narración y son necesariamente anticlimáticas: dejan en el espectador la sensación de que no ha pasado nada importante. Es una suerte de teatro del absurdo que resalta la incomprensión al hacer que los diálogos trabajen en contra de las imágenes.

Lo que para otros directores hubiese sido un error inadmisible, para Wenders es una estética. La calidad del sonido en Summer in the City es deficiente y soluciona el problema -no sólo por cuestiones financieras- haciendo que el personaje "doble" los diálogos en estilo indirecto sobre el sonido directo. Así, por ejemplo, se oye al personaje responder a la pregunta de su interlocutor sobre lo que hizo en el tiempo en el que no se habían visto: "un año en Stadelheim, tú debes de saberlo" y simultáneamente en off: "ella me preguntó qué era lo que había hecho en ese tiempo. Yo dije: un año en Stadelheim, y ella debía de saberlo". Reinhold Rauh explica: “Die Verdoppelung hat allerdings auch zum Effekt, daß in dem sowieso von sehr

\footnotetext{
${ }^{28}$ En relación con la historia y la imagen, la historia me parece un vampiro que trata de chupar la sangre de la imagen. Las imágenes son muy delicadas, un poco como los caracoles que se retraen cuando uno toca sus antenas. Las imágenes no quieren trabajar como un caballo, ni quieren cargar ni transportar mensajes o significados, metas o moral. Pero eso es exactamente lo que quieren las historias.

29 1969-71. Dirección, guión: Wim Wenders. Producción: Hochschule für Fernsehen und Film. Sonido: Gerhard Konrad. Música: The Kinks, Loving' Spoonful, Chuck Berry, Gene Vincent, The Troggs. Formato: 16 mm. 125 min. Con: Hans Zischler (Hans), Edda Kölch, Libgart Schwarz, Gerd Stein, Muriel Werner, Helmut Färber, Marie Bardischewski, Wim Wenders.
} 
wortkargen Charakteren getragenen Film der gesprochenen Sprache die Kommunikative Funktion ganz ausgetrieben wird" (1990: 25). ${ }^{30}$

Congruente con su estética, Wenders hace de las historias pretextos para tratar las formas. Sus preocupaciones primeras y primarias son el rock, las imágenes, la autenticidad y el movimiento. En sus filmes todos los demás elementos propios del cine, como son el tiempo, los personajes y los diálogos, por un lado; y, por otro, la historia, se subordinan a aquéllas. En su cinematografía, los largos planos son no sólo inevitables sino indispensables; renunciar a ello a favor de reglas preestablecidas lo obligaría a renunciar a sí mismo. En su obra el concepto de "economía del relato" no tiene ningún sentido ya que mostrar las cosas tal como son toma su tiempo y sólo el tiempo exhibe la continuidad de las imágenes, sin cortes que cambiarían necesariamente el concepto de las cosas que se muestran. Así, Wenders cambia las reglas de cómo contar historias.

Precisamente eso fue lo que lo llevó a filmar Die Angst des Tormanns beim Elfmeter (El miedo del portero al penalti), ${ }^{31}$ transposición al cine del tercer experimento narrativo de Peter Handke. En él, ambos ponen en juego el modelo y la realización del narrar, pues aunque pareciera que en este relato Handke da un paso atrás hacia el método realista en donde un personaje central vive una historia y la perspectiva del narrar domina, la historia se atora ya que descansa en la continuidad psicológica del personaje. El propio Handke explica:

Das Prinzip war, zu zeigen, wie sich jemanden die Gegenstände, die er wahrnimmt, infolge eines Ereignisses (eines Mordes) immer mehr versprachlichen und, indem die Bilder versprachlicht werden, auch zu Geboten und Verboten werden... Der Schizophrene nimmt also die Gegenstände als Anspielungen auf sich, als "Wortspiele" wahr... Das ist das Prinzip der Erzählung, nur da $\beta$ eben dieses Verfahren nicht auf einen Schizophrenen angewendet wird (sofern es überhaupt Schizophrene gibt), sondern auf einen "normalen" Helden, den Fußballtormann. Dieser Vorgang, Gegenstände als Normen zu sehen, soll eben nicht als krankhaft verharmlost, sondern als lebensüblich vorgestellt werden (Durzak, 1982: 68). ${ }^{32}$

\footnotetext{
30 "en todo caso, la duplicación tiene también como resultado el que en la película, de todas maneras sostenida por personajes sumamente lacónicos, el lenguaje pierda toda función comunicativa".

31 1971-72. Dirección, Wim Wenders. Producción: Producción 1 Filmverlag der Autoren, München; Telefilm AG, Viena. Guión: Wim Wenders, basado en la novela homónima de Peter Handke. Fotografía: Robby Müller. Edición: Peter Przygodda. Sonido: Rainer Lorenz, Martin Müller. Música: Jürgen Knieper. 35 mm, Eastman Color. 100 min.

${ }^{32}$ El principio era demostrar, cómo para alguien las cosas que percibe a consecuencia de un suceso (un asesinato) cada vez se transforman más en lenguaje y, en tanto que las imágenes se vuelven lenguaje, también se vuelven mandatos y prohibiciones... El esquizofrénico entonces percibe las cosas como insinuaciones, como "juego de
} 
Josef Bloch, quien antes de ser mecánico fue un famoso portero, confunde, desde las primeras líneas del relato, la representación de la realidad con la realidad misma: por ello se le vuelve problemática y pierde su lugar en ella. Ante este hecho reacciona violentamente y, en un acto reflejo, estrangula a una chica que conoce en un cine. Todo se concentra en un instante: se ha perdido todo contexto y el crimen radica en el total vacío (Kann, 1992: 173). A Josef Bloch el lenguaje se le convirtió en un reflejo automático, un lugar común, y al faltarle las palabras todo deja de existir.

El filme, explica Wenders, muestra lo que le fascinó en el texto de Handke:

Am Buch hat mich eigentlich weniger "Handke" interessiert als die Geschichte und die Art, wie etwas beschrieben wird, etwa der Wechsel von einem Satz zum anderen, wo man plötzlich ganz gespannt weiterliest, weil jeder Satz für sich ganz genau stimmt, so daß einem die Abfolge der Sätze plötzlich viel mehr interessiert, als die Abfolge der Handlung, wie es nun weitergeht oder was überhaupt passiert. [...] Diese Genauigkeit ist auch genau das, was mir Lust gemacht hat, den Film zu machen, und auch den Film auf eine ähnliche Art zu machen, nämlich in Bildern, die auf eine ähnliche Art aufeinanderfolgen wie die Sätze von Handke, also Bilder, die auch stimmen und genauso präzise sein müssen (1988a: 14). ${ }^{33}$

No hay nada oculto ni misterioso tras las imágenes del filme, pues trata de las imágenes que muestra: el espectador no se encuentra frente a una historia contada en imágenes sino frente a imágenes que al sucederse unas tras otras cuentan una historia: el portero Bloch es el voyeur de sus propias acciones. Señala Uwe Künzel: “Dieser von Beginn an auffällig schwerfällige Film erscheint -vor allem auch, wenn man den Handke-Text kennt- wie eine

palabras"... Ese es el principio de la narración, nada más que este método no se aplica a un esquizofrénico (en el caso de que existan los esquizofrénicos) sino en un protagonista "normal", en el portero. Este proceso de ver objetos como normas, precisamente no debería ser minimizado como enfermizo, sino presentado como algo normal en la vida.

${ }^{33}$ En realidad, del libro no me interesó tanto "Handke", sino la historia y la manera cómo describir algo, por ejemplo el cambio de una frase a la otra, donde de repente uno sigue leyendo completamente atento, porque cada frase en sí le es totalmente pertinente, de tal manera que uno está mucho más interesado en la sucesión de las frases que en la continuación de la trama, de lo que sigue o lo que va a pasar [...] Esta precisión es exactamente lo que tenía ganas de hacer, hacer la película y hacerla también de una manera similar a las frases de Handke; en fin, imágenes que también deben de ser correctas e igualmente precisas. 
permanente Rangelei zwischen den 'kostbaren' Sätzen der Protagonisten und den nicht weniger 'kostbaren' Bildern des Films"' (1981: 93) ${ }^{34}$

La fama que Wenders adquirió con Die Angst... lo lleva a realizar su sueño de viajar a América en donde vive una frustrante experiencia con Der scharlachrote Buchstabe ${ }^{35}$ (el rodaje de este filme de encargo estuvo envuelto en dificultades: desde la elección de los actores, pues Wenders quería a Rüdiger Vogler en el papel del pastor Dimmesdale, pero como era desconocido en EUA tuvo que elegir a Lou Castel, además de que los productores decidieron cortar 10 minutos y lo hicieron sobre el original por lo que se perdieron). Pero esta experiencia reafirma a Wenders en su estética y decide no perder su energía con proyectos que no le pertenecen al cien por ciento.

Un par de años después, Handke publica dos obras importantes en su literatura, Der kurze Brief zum langen Abschied (1974a) (Carta breve para un largo adiós) y Wunschloses Unglück (1974b) (Desgracia indeseada), dos textos autobiográficos en los que se interrelacionan experiencia real y ficción; en la primera, el protagonista es escritor y tiene la edad del autor; en la segunda, trata el suicidio de su madre. Handke borra las fronteras entre él mismo como autor y el yonarrador haciendo más evidente aún su necesidad/deseo de aprender sobre sí mismo por y en la literatura.

En Carta breve..., Handke prueba el modelo de la novela de educación (Bildungsroman) ${ }^{36}$ y actualiza también el motivo del viaje. Para Rolf Selbmann, quien inserta a Peter Handke en su capítulo sobre el siglo $\mathrm{XX}$, no es propiamente una novela del género; pero sí explora "den

\footnotetext{
34 "Esta película, desde un principio ostentosamente pesada -todavía más si uno conoce el texto de Handke- aparece como una permanente lucha entre las 'valiosas' oraciones del protagonista y las no menos 'valiosas' imágenes de la película".

35 1972. Dirección: Wim Wenders. Producción: Produktinn 1 Filmverlag der Autoren, München; WDR, Köln; Elias Querejeta, Madrid. Guión: Wim Wenders, Bernardo Fernández basado en la pieza Der Herr klagt über sein Volk in der Wildnis Amerika, a su vez basada en The Scarlet Letter de Nathaniel Hawthorne. Fotografía: Robby Müller. Edición: Peter Przygodda. Sonido: Christian Schubert. Música: Jürgen Knieper. 35 mm., Kodachroma. 90 min. Con Senta Berger (Hester Prynne), Hans Christian Blech (Chillingworth), Lou Castel (Dimmesdale), Yella Rottländer (Pearl), William Layton (Bellingham), Alfredo Mayo (Fuller), Angel Alvarez (Wilson), Yellena Samarina (Hibbins), Rafael Albaicin (Indio), Laura Currie (Sarah), Rüdiger Vogler (Marino).

${ }^{36}$ La tradición de la novela de formación en Alemania data del siglo XVIII; y en la segunda mitad del siglo se da la secularización de este concepto teológico. "Bildung umschreibt nicht mehr blo $\beta$ die Wirkung Gottes auf die Menschen, sondern umfaßt auch eine der Natur immanente Kraft" (Selbmann, 1994: 1) ("Formación ya no nada más se circunscribe al efecto de Dios sobre los humanos, sino que incluye también una fuerza inmanente de la naturaleza").
} 
Identifikationsmöglichkeiten um Bildungsromanhelden und ihren erstrebten und verweigerten Zielsetzungen" (1994: 162). ${ }^{37}$ Por su parte, para Manfred Durzak es, más bien, una "desilusionada novela de educación" dado que los sucesos no ocurren en el sentido de permitir alcanzar la integración armoniosa, como en la clásica novela de educación, sino en oposiciones, barreras de miedo y decepciones (1982: 106).

El yo-narrador de Carta breve... viaja, observa y lee. Estas "actividades" inciden en su mundo interior, en su experiencia del mundo concreto y le crean la necesidad de sumergirse en un proceso de desarrollo. Entre la historia interior y la historia exterior se establece una tensión en la que descansa la verdadera historia de la novela. A partir de la lectura del Gran Gatsby, el yo-narrador hace la siguiente reflexión: “Das Bedürfnis, anders zu werden als ich war, wurde plötzlich leibhaftig, wie ein Trieb. Ich überlegte, wie ich die Gefühle, die der große Gatsby bei mir möglich gemacht hatte, zeigen und in meiner Umgebung auch anwenden könnte" (1974a: 18)..$^{38}$

Así, las lecturas son el puente que lo conectan con el mundo exterior. A lo largo de casi todo el relato, el protagonista se acompaña con Enrique el verde de Gottfried Keller. Enrique deviene el punto de comparación con su pasado, con sus recuerdos. El viaje del yo-narrador ocurre más en su memoria y a través de su vida pasada que en el exterior. No obstante, en la segunda parte del libro, "Der lange Abschied" ("El largo adiós"), el personaje logra su desarrollo: siente por primera vez ganas de vivir, de volcarse hacia el mundo exterior y se convierte, finalmente, en otro: borrándose del relato deja la palabra a los otros.

Con su novela autobiográfica Desgracia indeseada, continúa el trabajo que inició alrededor de los recuerdos en Carta breve... A través de la vida de su madre, Handke habla de su propia historia y reflexiona: “Das Schreiben war nicht, wie ich am Anfang noch glaubte, eine Erinnerung an eine abgeschlossene Periode meines Lebens, sondern nur ein ständiges Gehabe von Erinnerung in der Form von Sätzen, die ein Abstandnehmen bloß behaupteten" (1974b:

\footnotetext{
37 “las posibilidades de identificación que rodean a los héroes de la novela de educación y con sus metas anheladas y negadas".

38 "La necesidad de ser diferente a lo que era, de pronto se personificó, como un instinto. Pensaba en cómo mostrar y aplicar en mi entorno los sentimientos que el gran Gatsby habría hecho posibles".
} 
99). ${ }^{39}$ En ese sentido, representa para Handke un nuevo problema literario que debe resolver: conciliar lo individual con lo general. Y lo hace, como afirma Volker Bohn, de una manera un tanto complicada: "nämlich zugleich als eines der Vermittlung sprachlicher Bewältigung in ihrer besonderen Bedeutung für den Autor (Schreibtätigkeit, Distanznehmen) und in ihrer möglichen generellen Bedeutung (als Geschichte, die geschrieben steht)" (1985: 144). ${ }^{40}$

Como Handke, prefiere descubrir la historia en el camino y con Desgracia indeseada se ve obligado a "narrar posteriormente", lo contrario a su proyecto como escritor de "narrar anticipadamente" (1990: 26), esta obra le representa un doble peligro: “einmal das bloße Nacherzählen, dann das schmerzlose Verschwinden einer Person in poetischen Sätzen" (1974b: 44). ${ }^{41}$ Así pues, ser parte de la historia y a la vez tener que distanciarse para contarla, lo lleva a iniciar el camino de su narración con un modelo diferente al de la biografía decimonónica.

Mientras Handke se reconcilia con su vida, Wenders hace lo suyo descubriendo su propio estilo. En Alicia en las ciudades, ${ }^{42}$ plantea el problema de la realidad frente a la representación: las dos expresan significaciones diferentes. El escritor Philip viaja por EUA con el fin de encontrar la inspiración para escribir un libro; pero, asediado por las imágenes, no puede escribir y en su necesidad de asir la realidad se dedica a tomar fotos con una cámara Polaroid (que por cierto en ese año aún no salían al mercado), lo que le permite comparar, en el mismo momento en el que toma la foto, la imagen con la realidad. El escritor exclama, al ver sus fotos, que nunca sale lo que realmente acaba de ver. La realidad se revela inasible, resulta imposible percibirla tal cual en la representación fotográfica.

Alicia en las Ciudades es considerada la primera típica película wendersiana. Con ella comienza la trilogía de los road movies a la cual pertenecen también Falsche Bewegung (Falso Movimiento) y Im Lauf der Zeit (En el transcurso del tiempo) (Rauh, 1990: 37). Aún cuando el propio

\footnotetext{
39 "Escribir no era, como yo aún pensaba en un principio, memoria de un periodo terminado de mi vida, sino una afectación permanente de recuerdos en forma de frases, las que sólo pretenden la toma de distancia".

40 "a la vez como mediación de dominio lingüístico, en su especial significado para el autor (actividad de escribir, tomar distancia) y en su posible significado general (como historia, que está escrita)".

41 "primero la pura narración, luego el desvanecimiento indoloro de una persona en frases poéticas".

42 1973-74. Dirección: Wim Wenders. Producción: Produktion 1 Filmverlag der Autoren, München; WDR, Köln. Guión: Wim Wenders, Veith von Fürstenberg. Fotografía: Robby Müller. Edición: Peter Przygodda. Sonido: Martin Müller, Paul Schöler. Música: Can, Chuck Berry, Canned Heat, Deep Purple, Count Five, The Stories. 16 mm. Con: Rüdiger Vogler (Philip Winter), Yella Rottländer (Alice), Lisa Kreuzer (Lisa van Damm), Edda Köchl (Amiga), Didi Petrikat, Hans Hirschmüller, Sam Presti, Lois Moran, Ernst Böhm, Mirko, Sibylle Baier. 110 min.
} 
Wenders no los haya filmado con esa intención, Stefan Kolditz también ve una trilogía en estos filmes (1992: 146).

In drei Filmen hat Wenders Deutschland ausgemessen: aus der Fremde ist er in ein Land gekommen, das seine Heimat hätte sein sollen (ALICE); er hat der Einsamkeit, der Vergangenheit und dem unkreativen Klima von Nord nach Süd, vom Meer bis zu den Alpen nachgespürt (FALSCHE BEWEGUNG); und er hat schießlich den Zustand des geteilten Deutschland anhand der verrotteten Kinoprovinz beschrieben, in dem jede Bewegung zum Selbstzweck wird, wo jedes Ende monoton in den Anfang mündet wie die Schleife des Pornofilms, die Bruno Pauline vorführt (IM LAUF DER ZEIT) (Buchka, 1985: 76).43

Tres filmes que confirman el camino del cineasta con el viaje como motivo nuclear y como metáfora del conocimiento, cuyos personajes centrales lo alcanzan en el movimiento geográfico. Son personajes despatriados para los que el movimiento es también necesario en la búsqueda del hogar y por extensión de la propia identidad. Y, como en los personajes handkeanos, resalta una incapacidad de comunicación que evidencia su desconfianza en la palabra en donde las acciones y los diálogos siguen caminos propios. Wenders hace de esta trilogía una reflexión sobre el cine mismo como "el medio mecánico de crear la ilusión de movimiento en la pantalla" (Arnheim, 1986: 131).

En Falsche Bewegung, ${ }^{44}$ el color enfatiza el carácter doblemente ficticio de la obra; es decir, tanto los personajes como la historia del filme salen a su vez de la ficción de Peter Handke.

Wir haben uns (mit Handke) unheimlich bemüht, den Wilhelm nie was ganz richtiges machen zu lassen, überhaupt alle Figuren. Auch die Beziehungen zwischen ihnen haben wir nicht eindeutig gut und falsch sein lassen, sondern immer so, wie es im Film eigentlich nie dargestellt worden ist: immer auf der Kippe zwischen falsch und richtig. Mal denkt man, Wilhelm hat was richtig

\footnotetext{
${ }^{43}$ En tres películas Wenders ha medido Alemania: del extranjero llegó a un país que debió ser su patria (ALICE); indagó sobre la soledad, el pasado y el clima no creativo de norte a sur, desde el mar hasta los Alpes (FALSO MOVIMIENTO); y finalmente, ha retratado la condición de la Alemania dividida mediante la descripción de lo podrido del cine de provincia, en el cual cada movimiento es un fin en sí, en donde cada fin de manera monótona lleva al principio, como el 'loop' de la cinta del rollo pornográfico que muestra Bruno a Pauline (EN EL TRANSCURSO).

44 1974. Dirección: Wim Wenders. Producción: Solaris Film, München; WDR, Köln. Guión: Peter Handke, versión libre del Wilhelm Meisters Lehrjahre de Wolfgang von Goethe. Fotografía: Robby Müller. Edición: Peter Przygodda. Sonido: Martin Müller, Peter Kaiser, Paul Schöler. Música: Jürgen Knieper. 35 mm., Eastman Color. 103 min. Con: Rüdiger Vogler (Wilhelm), Hanna Schygulla (Therese), Hans Christian Blech (Laertes), Nastassja Kinski (Mignon), Peter Kern (Barnard Landau), Ivan Desny (Industrial), Marianne Hoppe (Madre), Lisa Kreuzer (Janine), Adolf Hansen (Controlador).
} 
gemacht, im nächsten Moment sieht man, er hat es gar nicht gemerkt, und er zerstört alles wieder. Deswegen heißt der Film FALSCHE BEWEGUNG (Rauh, 1990: 46). ${ }^{45}$

Los personajes son obviamente Kunstfiguren (figuras ficcionales), al contrario de los personajes de Alicia... y de En el transcurso..., que parecen salir de la realidad, son absolutamente teatrales; teatralidad que es reforzada por los diálogos. Es un filme insólito por su explícito simbolismo.

Además, este experimento conjunto logra actualizar el modelo del Bildungsroman. En la conjunción de los dos medios, la literatura y el cine, se agita una corriente subterránea que hace de Falsche Bewegung un filme de formación y una novela de viaje: el movimiento que exige el género, en vez de ocurrir predominantemente en el interior del personaje y en sus experiencias, se observa en el mundo exterior como en el road movie. Falsche Bewegung es una muestra de su trabajo en conjunto que, por sus características formales y de contenido, representa la obra par excellence uniendo a dos artistas que se expresan en diferentes medios, con lenguajes diferentes, pero con una misma estética. Resulta una reflexión única sobre la interacción entre escribir, política, espectáculo, hacer películas e historia.

Con El transcurso del tiempo, ${ }^{46}$ Wenders regresa al blanco y negro. La última película de la trilogía del viaje lleva la reflexión sobre el cine más allá: la muerte del cine como industria. Para ello, Wenders crea un personaje cuyo trabajo consiste en reparar proyectores en los viejos cines de una olvidada región alemana que, en ese entonces, hacía frontera con la Alemania oriental y muestra el panorama desolador de salas cinematográficas que sobreviven a duras penas. ${ }^{47}$

\footnotetext{
${ }^{45}$ Nos esforzamos mucho (con Handke) para que Wilhelm nunca hiciera algo totalmente correcto, y en general, lo mismo con todos los personajes. Tampoco dejamos que las relaciones entre ellos fueran inequívocamente buenas o falsas sino más bien siempre, como nunca se ha presentado en el cine: siempre a punto de caer entre lo falso y lo correcto. Alguna vez uno piensa que Wilhelm hizo algo correcto, en el momento siguiente se ve que él ni se ha dado cuenta y otra vez destruye todo. Por eso la película se llama FALSO MOVIMIENTO.

46 1975. Dirección: Wim Wenders. Producción: Wim Wenders Produktion, München; WDR, Köln. Guión: Wim Wenders. Fotografía: Robby Müller. Edición: Peter Przygodda. Sonido: Martin Müller, Bruno Bollhalder. Música: Improved Sound Limited. 35 mm. 175 min. Con: Rüdiger Vogler (Bruno), Hans Zischler (Kamikaze), Lisa Kreuzer (Pauline), Rudolf Schündler (Padre).

${ }^{47}$ La muerte del cine será el tema central del documental que siete años después realizará en Cannes. En Chambre 666 ( $N$ 'importe quand ... ); en él muestra a quince directores de cine, entre los que se encuentran -por citar algunosGodard, Fassbinder, Antonioni, Herzog, Spielberg, quienes, uno a la vez, responden frente a una cámara, que instaló en el cuarto 666 del Hotel Martínez, a la pregunta: “Ist das Kino eine Sprache, die uns verlorengeht, eine Kunst, die
} 
Siguiendo el principio del road movie, fue filmada cronológicamente. Más aún, con esta película Wenders lleva su gusto/necesidad por el experimento al extremo de escribir el guión en el transcurso de la filmación: durante las noches escribe los diálogos que se filmarían al día siguiente. Tarea nada fácil, pues la filmación no podía alargarse infinitamente, sobre todo por cuestiones económicas: por primera vez Wenders entendió la relación entre ideas y dinero (1988a: 26) pues en una ocasión tardó dos días en escribir el diálogo mientras el equipo en pleno esperaba sin poder hacer nada. Tal fue su angustia que juró que su próximo filme tendría un guión.

Wenders explica que -al menos hasta El estado de las cosas- su filmografía alterna películas que llama del "Tipo A" -aquéllas que no siguen una historia preestablecida- y las del “Tipo B" -las que siguen claramente una historia, en donde todos los que en ella trabajan saben en qué terminará y cómo se desarrolla. Las películas " $\mathrm{A}$ " son una reacción a las películas " $\mathrm{B}$ " y viceversa: filmar las primeras desespera al cineasta, en el sentido de que la película se hace sobre la marcha y el factor económico es una presión, y, sin embargo, las segundas llegan a aburrirlo porque siguen una estructura rígida y los actores interpretan a otro, al contrario de las películas "A" en las que los actores se interpretan a sí mismos (1988a: 74). En todos los filmes se presentan constantes claras: los tipo " $\mathrm{A}$ " son en blanco y negro, los " $\mathrm{B}$ " en color; en todos se repite el tema del viaje y todos cuentan lo inenarrable a la vez que reflexionan sobre el cine mismo.

La cámara de En el transcurso... sigue los hechos de la vida cotidiana, no hay dramatización: en este filme se muestra a dos hombres, quienes por azares de la vida se encuentran, y su comportamiento en esa extraña situación que ninguno de los dos buscó. "Keine einzige Einstellung in diesem Film ist als Metapher, als Symbol lesbar, sondern die Bilder spiegeln immer nur real Gewesenes wieder" (Künzel, 1981: 106).48 Al contrario que en Falsche Bewegung los diálogos son escasos y simples. La búsqueda de palabras que no se

schon im Untergang begriffen ist?” (“¿Es el cine un lenguaje, un arte, que se nos va, que ya está agotado?”) entre otras preguntas en el mismo tenor (Wenders, 1988a: 35-52).

48 "Ninguna toma en este filme puede ser leída como metáfora o símbolo, más bien las imágenes reflejan nada más lo realmente sucedido". 
encuentran se ve magnificada ante el inminente fin del otro lenguaje que es el cine (Kolditz, 1992: 177).

Los personajes de la trilogía de los road movies viajan permanentemente en avión, en auto, en tren..., paran en estaciones de tren y en aeropuertos, pernoctan en hoteles, en casas de conocidos o desconocidos y comen en restaurantes: los personajes wendersianos sólo en el viaje están en casa. Se trata de tres filmes que no cuentan historias extraordinarias porque las historias son las imágenes.

El estado de las cosas,"49 último filme del grupo "A", es un parteaguas en la obra wendersiana. A partir de una paradoja resuelve su dilema: la película trata de un equipo de cine al que se le acaba el negativo para poder seguir filmando, y habla de la imposibilidad de contar una historia en el cine. Es, como el propio Wenders la llama, una película-tesis. Munro, el alter ego de Wenders, reflexiona:

Ich habe zehn Filme gemacht. Und immer die gleiche Geschichte erzählt. Am Anfang war es ganz leicht. Da ging's von Einstellung zu Einstellung. Aber jetzt habe ich Angst am Abend vorher. Jetzt weiß ich, wie das Erzählen geht -und unweigerlich läuft den Geschichten das Leben aus und sie sind tot. Geschichten haben einfach zu viel Regeln, Mechanismen. Tod, das ist die große Geschichte. Davon handeln sie alle. Todesboten. Der Tod, darum dreht sich doch alles. Nur Liebesgeschichten sind größer (Rauh, 1990: 83).50

Sin embargo, el director Munro -ya en Hollywood, en donde cree poder conseguir el dinero necesario para continuar con su película- se ve envuelto en una historia como ésas en las que no cree. A estas alturas de su producción, Wenders encuentra que las historias son necesarias; pero no en el sentido de entretenimiento que “...erzählen nämlich nur noch die

\footnotetext{
49 1981. Dirección: Wim Wenders. Producción: Road Movies, Berlin; Wim Wenders Produktion, München; Gray City Inc., New York; Pro-ject Filmproduktion, München; ZDF, Mainz; Paris Films, París; Musidora, Madrid; Film International, Rotterdam; Artificial Eye, London. Guión: Wim Wenders, Robert Kramer. Fotografía: Henri Alekan, Martin Schäfer, Fred Murphy. Edición: Barbara von Weitershausen, Peter Przygodda. Sonido: Maryte Kavaliauskas, Martin Müller. Müsica: Jürgen Knieper. $35 \mathrm{~mm}$. $120 \mathrm{~min}$. Con: Patrick Bauchau (Friedrich Munro), Isabelle Weingarten (Anna), Rebecca Pauly (Joan), Jeffrey Kime (Mark), Geoffrey Carey (Robert), Camila Mora (Julia), Alexandra Auder (Jane), Paul Getty III (Dennis), Viva Auder (Kate).

${ }^{50}$ He hecho diez películas y siempre he contado la misma historia. Al principio era muy fácil. Iba de toma en toma. Pero ahora, la noche anterior, tengo miedo. Ahora sé cómo es narrar -e inevitablemente a las historias se les va la vida y mueren. Las historias tienen sencillamente demasiadas reglas, mecanismos. La muerte, esa es la gran historia. De ella tratan todas. Mensajeros de la muerte. Todo gira alrededor de la muerte. Solamente las historias de amor son más grandes.
} 
affirmative Form der Geschichte, ihre Höhepunkte, als eine Art von 'Schaufliegen'" (1988a: 61),51 sino que, y dado que no hay nada nuevo que contar, son sólo necesarias para dar un cierto orden a las vidas de los seres humanos, para afirmarse competentes en determinar su vida (1988a: 59). Esta película representa un avance en el trabajo del cineasta pues a partir de ella inicia una nueva etapa con la idea de que si bien las historias son imposibles, sin ellas es imposible vivir, por ello El estado de las cosas es una experiencia inevitable y consecuente en su obra.

Ich habe mich mit dem Schlu $\beta$ des Films willentlich in eine Position gebracht, die mich dazu zwingt, meine andere Vorstellung vom heutigen oder künftigen Kino einzulösen: Nämlich ein wieder mögliches Erzählen zu zeigen oder die Schnauze zu halten. Und das möchte ich in den nächsten beiden Filmen versuchen. Da möchte ich wieder ein Erzählen versuchen: das ganz rabiat und ganz selbstsicher den Bezug von Filmsprache auf das Leben hernimmt und das es aufgibt, das Erzählen mit der Darstellung seiner Bedingungen zu verknüpfen. Damit man eben das Feld nicht den großen Spektakel-Filmen überläßt, sondern ganz selbsbewußt hingeht und Geschichten erzählt -ohne das Bedauern oder den Rückblick auf das schöne GeschichtenErzählen, das es früher mal im Kino gab. Nach vornehin erzählen, das will ich (1988a: 62).52

Así, descubre la necesidad de la historia y, sin alejarse de su línea, empieza a confiar en ella. Paris, Texas ${ }^{53}$ da cuenta de ello. En este filme la historia sucede antes: la película empieza en donde la historia termina. Travis viaja, pero en un sentido diferente de los personajes de la trilogía, porque huye de su propia historia, a la vez que en ese viaje recupera su pasado. Por primera vez Wenders explora la relación entre un hombre y una mujer; por primera vez el diálogo culmina en una comunicación real: Paris, Texas es “weniger ein Road movie denn ein

\footnotetext{
51 "narran nada más la forma afirmativa de la historia, sus puntos culminantes, como una 'demostración de vuelo"”.

${ }^{52}$ Hacia el final de la película me puse, a propósito, en una posición que me obligaba a cumplir con mi idea del cine de hoy o mañana; es decir, demostrar una vez más una posible forma de narrar o cerrar el pico. Y esto quiero inventar en las próximas dos películas. En ellas quiero probar otra vez un tipo de narración: que toma estrictamente, y totalmente segura de sí misma, la relación entre el lenguaje del cine y la vida y que deja de relacionar la narración con la representación de sus condiciones. Para no dejar el campo a las películas de gran espectáculo, sino, seguro de uno mismo contar historias -sin lamentos o nostalgia sobre lo bello que era narrar, como fue en el cine anteriormente. Narrar hacia adelante, eso es lo que quiero.

53 1983-84. Dirección: Wim Wenders. Producción: Road Movies, Berlin; Argos Film, Paris; WDR, Köln, Channel 4 , London; Pro-ject Filmproduktion. Guión: Sam Shepard. Cámara: Robby Müller. Edición: Peter Przygodda. Sonido: Jean Paul Mugel. Música: Ry Cooder. 35 mm. 148 min. Con: Harry Dean Staton (Travis), Nastassje Kinski (Jane), Dean Stockwell (Walt), Aurore Clémente (Anne), Hunter Carson (Hunter).
} 
essayistisches talkie, das anspricht, worum es geht, ohne die Dinge zu zerreden" (Grob, 1991: 249). ${ }^{54}$ Es, efectivamente, una nueva dimensión en la filmografía wendersiana.

El transcurso del tiempo también ayudó a Peter Handke a madurar sus posturas: desde su primera obra se rige por la contradicción, la negación; parte de estructuras conocidas para, en el camino, derrumbarlas. La destrucción es lo que le permite avanzar y esperar la novedad de lo que surja: "siempre son las dos cosas: construcción, y luego esa esperanza quizá ridícula de que en el trabajo se me dé indirectamente, que de una cosa que siempre careció de significado se convierta en el relato en alguna clase de cosa-fin o cosa-sentido" (1990: 25). En ese mismo sentido, los filmes de Wenders son contemplativos: su cámara registra sin cortes, sin movimientos, sin zooms; es una cámara estática y, por ello, curiosa; es una reflexión sobre el cine mismo.

De modo que los años setenta representan para estos dos autores una época de gran creatividad que continúa hasta hoy. Estos ejemplos paradigmáticos de sus obras dan cuenta de la búsqueda de nuevas formas y de un trabajo en conjunto singular en la relación entre literatura y cine.

54 "menos un road movie que un talkie ensayístico, que aborda de qué se trata sin demoler las cosas". 


\section{Bibliografía}

ARNHEIM, Rudolf (1986): El cine como arte, Barcelona: Paidós.

BOHN, Volker (1985): “'Später werde ich über das alles Genaueres schreiben'. Peter Handkes Erzählung Wunschloses Unglück aus literaturtheoretischer Sicht". En Peter Handke (ed. Raymund Fellinger), Frankfurt am Main: Suhrkamp, pp. 140-167.

BRAUN, Michael (1989): “Die Sehnsucht nach dem idealen Erzähler. Peter Handkes romantische Utopie”. En Text+Kritik 24 (ed. Heinz Ludwig Arnold), München: Edition text + kritik Verlag, pp. 73-81.

BUCHKA, Peter (1985): Augen kann man nicht kaufen, Frankfurt am Main: Fischer Taschenbuch Verlag.

DITTBERNER, Hugo (1989): “Der panische Übersetzer. Zu Peter Handke”. En Text+Kritik 24 (ed. Heinz Ludwig Arnold), München: Edition text + kritik Verlag, pp. 3-7.

DURZAK, Manfred (1982): Peter Handke und die deutsche Gegenwartsliteratur, Stuttgart: Kohlhammer. GROB, Norbert (1991): Wenders, Berlin: Edtion Filme.

HANDKE, Peter (1972a): Die Angst des Tormanns beim Elfmeter, Frankfurt am Main: Suhrkamp.

- (1966a): Die Hornissen, Frankfurt: Suhrkamp.

- (1974a): Der kurze Brief zum langen Abschied, Frankfurt: Surhkamp.

- (1972b): Ich bin ein Bewohner des Elfenbeinturms, Frankfurt: Suhrkamp.

- (1968): Kaspar, Frankfurt: Suhrkamp.

- (1990): Pero yo vivo solamente de los intersticios, Barcelona: Gedisa.

- (1966b): Publikumbeschimpfung und andere Sprechstücke, Frankfurt: Suhrkamp.

- (1985): “Über meinen neuen Roman Der Hausierer". En Peter Handke (ed. Raymund Fellinger), Frankfurt am Main: Suhrkamp, pp. 140-167.

- (1974b): Wunschloses Unglück, Frankfurt. Suhrkamp.

HANSEN, Olaf (1985): “Die Muse Atropos. Überlegungen zu Peter Handke als schwierigem Erzähler”. En Peter Handke (ed. Raymund Fellinger), Frankfurt am Main: Suhrkamp, pp. 196-226

KANN, Irene (1992): Schuld und Zeit. Literarische Handlung in Theologischer Sicht. Thomas Mann, Robert Musil, Peter Handke, Paderborn: Ferdinand Schöningh.

KESTING, Mariane (1981): “Das deutsche Drama vom Ende des 2. Weltkriegs bis Ende der sechziger Jahre". En Deutsche Gegenwartsliteratur. Ausgangspositionen und aktuelle Entwicklungen, Stuttgart: Philipp Reclam, pp. 124-128.

KOLDITZ, Stefan (1992): “Kommentierte Filmografie”. En Reihe Film 44. Wim Wenders, Frida Grafe et alt. München: Carl Hanser Verlag, pp. 103-290.

KÜNZEL, Uwe (1981): Wim Wenders. Ein Filmbuch, Freiburg: Dreisam Verlag.

LORENZ, Otto (1989): “Literatur als Widerspruch". En Text+Kritik 24, (ed. Heinz Ludwig Arnold), München: Edition text + kritik Verlag, pp. 8-16.

MIXNER, Manfred (1977): Peter Handke, Kronberg: Athenium-Verlag. PÜTZ, Peter (1982): Peter Handke. Frankfurt am Main: Suhrkamp.

RAUH, Reinhold (1990): Wim Wenders, München: Satz.

SELBMANN, Rolf (1994): Der Deutsche Bildungsroman, Stuttgart: J.B.Metzler.

WENDERS, Wim (1988a): Die Logik der Bilder, Frankfurt am Main: Verlag der Autoren.

- (1988b): Emotion Pictures. Essays und Filmkritiken. 1968-1984, Frankfurt am Main: Verlag der Autoren. 